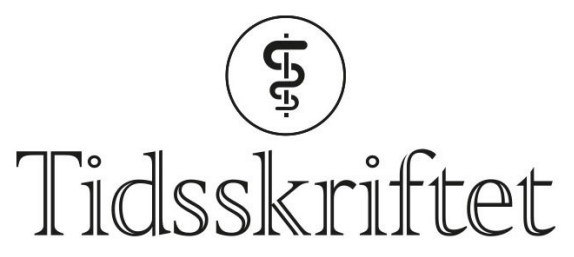

DEN NORSKE LEGEFORENING

\title{
Kvetiapin er ikke en sovemedisin
}

KRONIKK

\section{KAREN ASTRID BOLDINGH DEBERNARD}

Karen Astrid Boldingh Debernard er cand.pharm., ph.d. og spesialrådgiver ved RELIS Sør-Øst, Avdeling for klinisk farmakologi og Avdeling for kompleks epilepsi, Oslo universitetssykehus.

Forfatteren har fylt ut ICMJE-skjemaet og oppgir ingen interessekonflikter.

\section{JOACHIM FROST}

Joachim Frost er spesialist i klinisk farmakologi, ph.d. og overlege ved Avdeling for klinisk farmakologi, St. Olavs hospital.

Forfatteren har fylt ut ICMJE-skjemaet og oppgir ingen interessekonflikter.

\section{PÅL-DIDRIK HOFF ROLAND}

E-post:didrik@relis.no

Pål-Didrik Hoff Roland er cand.pharm. og legemiddelrådgiver ved RELIS Midt-Norge, Avdeling for klinisk farmakologi, St. Olavs hospital.

Forfatteren har fylt ut ICMJE-skjemaet og oppgir ingen interessekonflikter.

Bruk av antipsykotikumet kvetiapin for behandling av søvnproblemer har fått betydelig omfang, også i Norge. Nytten er dårlig dokumentert, og selv lave doser kan gi vesentlige bivirkninger. Det er grunn til å advare mot slik forskrivning.

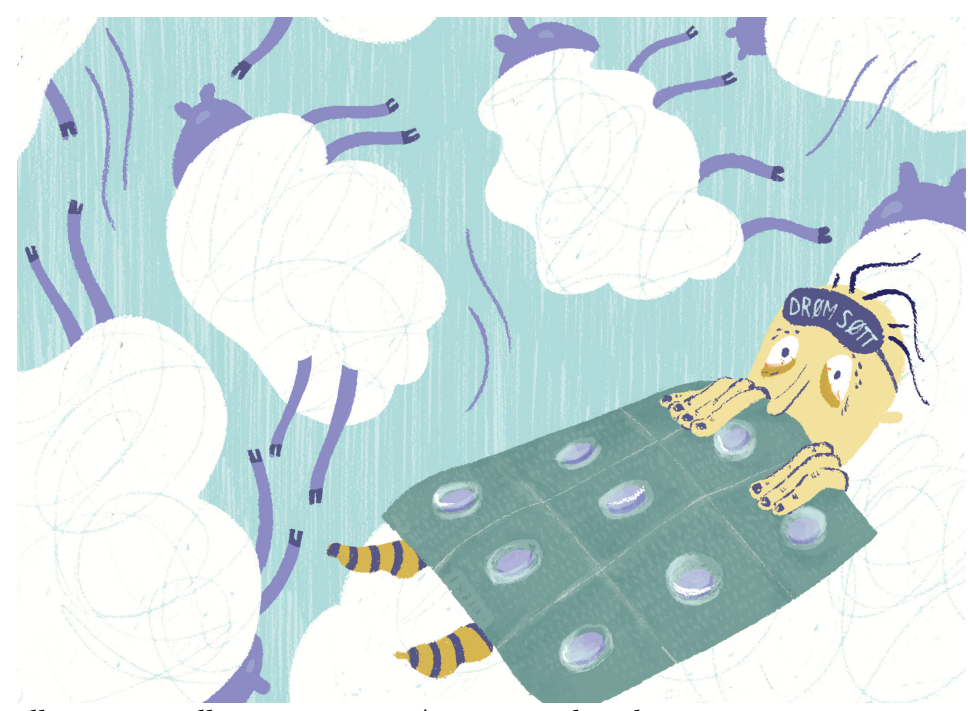

Illustrasjon: illustratorene.no/Marius Pålerud

Kvetiapin er et andregenerasjons antipsykotikum med godkjent indikasjon for behandling av schizofreni og bipolar lidelse samt tilleggsbehandling ved depresjon. Anbefalt dosering ved disse indikasjonene er 300-80o mg per døgn. Søvnighet er en svært vanlig bivirkning (> $10 \%)$ av legemidlet. De senere årene har det vært en økende forskriving av kvetiapin i doser 
på 25-10o mg for behandling av insomni (1, 2). Også i Norge er dette blitt en utbredt praksis, inkludert til barn, ungdom og eldre. Dette fremgår blant annet av spørsmål stilt til de regionale legemiddelinformasjonssentrene (RELIS). En ny, norsk studie for perioden 2004-17 har vist at median forskrevet daglig dosering av kvetiapin i Norge ligger under $100 \mathrm{mg}$, og at omtrent $4 \%$ av brukerne fikk doser og refusjon forenlig med bruk av kvetiapin på godkjent indikasjon (3).

\section{Kvetiapin og søvn}

Tross utbredt bruk av lavdose kvetiapin ved insomni er effekt og sikkerhet på denne indikasjonen dårlig dokumentert i kliniske studier (4-6). Det er gjennomført bare én randomisert studie av effekt ved primær insomni, og denne hadde 13 pasienter (7). Resultatene var inkonklusive. En åpen, ikke-kontrollert studie over seks uker med 18 pasienter med primær insomni viste bedring for enkelte av de subjektive søvnparametrene (Pittsburgh Sleep Quality Index), men tid til innsovning ble ikke redusert (8).

I flere av studiene med kvetiapin ved psykoser, bipolar lidelse eller depresjon er effekter på søvn også undersøkt $(9,10)$. Det er vanskelig å skille positive effekter av behandling på primærlidelsen og ledsagende søvnvansker, men det er i disse studiene sett at kvetiapin også kan ha negativ effekt på søvn hos pasienter med schizofreni (10).

Tre oversiktsartikler fra årene 2014-18 konkluderer alle med at bruk av kvetiapin mot insomni ikke er tilrådelig, hovedsakelig på grunn av manglende dokumentasjon (4-6). Den første av disse konkluderer med at nytte-risiko-profilen ved bruk mot insomni er ufordelaktig selv hos pasienter med annen indikasjon for bruk av kvetiapin (4).

Det antas at sentral histamin H1-reseptorblokade, og i mindre grad alfa-1-antiadrenerge og antimuskarinerge egenskaper er viktige for kvetiapins sederende effekt $(11,12)$. Det er anslått at nær 100 \% av H1-reseptorene og over 50 \% av serotonin 5 HT2a- og dopamin D2reseptorene blir blokkert allerede ved bruk av $50 \mathrm{mg}$ kvetiapin (12). Det er med andre ord holdepunkter for at kvetiapin utøver effekt på flere reseptorsystemer også ved lave doser.

I studier av kvetiapin hos pasienter med schizofreni, hvor det brukes høyere doser, oppgis det at søvnighet som bivirkning i liten grad øker med dose, men de fleste opplever toleranseutvikling, slik at sedasjon er mindre uttalt ved bruk over flere uker (10). Det er rimelig å anta at dette også gjelder når kvetiapin brukes ved insomni. Toleranseutvikling er også kjent for sederende antihistaminer, som blant annet har vært benyttet mot søvnvansker. Bruk av mangelfullt dokumenterte legemidler med effekt på mange reseptorsystemer ved insomni er ikke nytt i Norge, og er også tidligere omtalt i Tidsskriftet (14).

\section{Bivirkninger ved bruk av lavdose kvetiapin}

Bruk av kvetiapin medfører betydelig bivirkningsrisiko også ved lave doser. Blant annet er vektøkning og metabolske forstyrrelser, inkludert $ø$ kning i triglyserider, rapportert ved lave doser kvetiapin (15-17). Sedasjon på dagtid («hangover») er hyppig rapportert (7-9, 15-17). Blant andre observerte bivirkninger av lavdose kvetiapin er urolige bein, akatisi, munntørrhet og redusert oppmerksomhet $(5,9,18,19)$.

Vi er ikke kjent med retningslinjer som tilrår bruk av kvetiapin for behandling av insomni

Studier utover to uker finnes ikke, slik at langtidseffekt av lavdose kvetiapinbehandling er ukjent. Doseeskalering er rapportert ved bruk av kvetiapin mot primær insomni, og mange pasienter rapporterer om problemer med å seponere kvetiapin etter lavdosert bruk (13). Det er også holdepunkter for at kvetiapin har misbrukspotensial (20). 


\section{Kvetiapin og retningslinjer for behandling av insomni}

Ved akutt insomni kan medikamentell behandling være til hjelp. Tradisjonelle hypnotika (z-hypnotika og noen benzodiazepiner) har godkjent indikasjon for kortvarig bruk ( $<2-4$ uker) og kan da være førstevalg. Toleranseutvikling og risiko for avhengighet begrenser bruk av disse midlene over tid, og det er heller ikke god dokumentasjon for at hypnotika har effekt ved kroniske søvnvansker. Ved kronisk insomni anbefales andre tiltak som søvnhygieneråd og kognitiv terapi med fokus på søvn (CBT-I, cognitive behavioral therapy for insomnia). Inntil $80 \%$ har effekt av slik behandling $(21,22)$.

Vi er ikke kjent med retningslinjer som tilrår bruk av kvetiapin (eller andre antipsykotika) for behandling av insomni. Norske nasjonale anbefalinger uttrykker bekymring og er negative til den $\emptyset$ kte bruken av antipsykotika ved insomni (22). Europeiske og amerikanske retningslinjer slår fast at kvetiapin ikke anbefales ved insomni på grunn av utilstrekkelig dokumentasjon og betydelige bivirkninger $(23,24)$. Norsk elektronisk legehåndbok (NEL) og britiske anbefalinger (BMJ Best Practice) omtaler ikke kvetiapin ved søvnproblemer (25, 26). UpToDate, et amerikansk "point of care»-oppslagsverk for leger, omtaler bare kvetiapin ved insomni til pasienter med misbruksproblematikk, og advarer mot manglende dokumentasjon og vesentlig bivirkningsrisko $(27,28)$.

Det europeiske legemiddelbyrå (EMA) gjennomførte en harmonisering av preparatomtalen for kvetiapin i Europa i 2014. Verken i Europa eller i USA er søvnproblemer blant godkjente indikasjoner $(29,30)$.

\section{Manglende dokumentasjon og godkjenning}

Det er vårt inntrykk at lavdose kvetiapin brukes som et alternativ til hypnotika med vanedannende egenskaper. Dette er også tidligere omtalt i Tidsskriftet (31).Vi erfarer dessuten at lavdose kvetiapin forskrives til pasienter hvor tankekjør og grubling gjør innsovning vanskelig, også innen barne- og ungdomspsykiatrien. Tanken bak forskrivningen er da tilsynelatende at man ønsker «litt antipsykotisk effekt» for å dempe dette. Det er viktig å være klar over at effektdokumentasjon for kvetiapin gjelder andre indikasjoner og høyere doser, og at det ikke foreligger dokumentasjon fra kliniske studier til å forsvare slik forskrivning. Derimot er det gode holdepunkter for at kvetiapin kan gi betydelige bivirkninger også i lave doser.

Leger må være oppmerksomme på at man ved bruk av kvetiapin ved insomni forskriver utenfor godkjent indikasjon

Til pasienter med psykose kan det tenkes tilfeller der det er hensiktsmessig å velge et antipsykotikum med uttalt sedativ effekt, særlig i akutt fase (4, 21). Det er likevel ikke grunnlag for å anbefale tillegg av lavdose kvetiapin for søvn til annen behandling med antipsykotika hos denne pasientgruppen, spesielt ikke over tid. Dette er pasienter som allerede har stor bivirkningsbelastning, mer sykdom og økt dødelighet. Sedasjon på dagtid kan være uheldig (7-9), og kvetiapins nytte mot insomni er ikke vist å oppveie risikoen hos slike pasienter (4). Andre alternativer bør derfor vurderes først også hos disse pasientene.

Kvetiapin har blitt omfattende markedsført til bruk utenfor godkjent indikasjon, deriblant insomni, og produsenten AstraZeneca er bøtelagt for dette i USA (32). Kollegers forskrivning av kvetiapin mot søvnvansker er også en faktor som kan medføre en overvurdering av det faktiske kunnskapsgrunnlaget. Leger må være oppmerksomme på at man ved bruk av kvetiapin ved insomni forskriver utenfor godkjent indikasjon og dermed påtar seg et større ansvar for å vurdere forsvarligheten, ikke minst med hensyn til pasientens sikkerhet.

Det er etter vårt skjønn utviklet et uheldig forskrivningsmønster når antipsykotikumet kvetiapin brukes i betydelig omfang for behandling av insomni uten at effekt eller sikkerhet av denne behandlingen er tilstrekkelig dokumentert. Kvetiapin er ikke en sovemedisin, og bør etter vår mening heller ikke brukes som det. 
1. Pringsheim T, Gardner DM. Dispensed prescriptions for quetiapine and other second-generation antipsychotics in Canada from 2005 to 2012: a descriptive study. CMAJ Open 2014; 2: E225-32. [PubMed][CrossRef]

2. Kamphuis J, Taxis K, Schuiling-Veninga CC et al. Off-label prescriptions of low-dose quetiapine and mirtazapine for insomnia in The Netherlands. J Clin Psychopharmacol 2015; 35: 468-70. [PubMed]

3. Gjerden P, Bramness JG, Tvete IF et al. The antipsychotic agent quetiapine is increasingly not used as such: dispensed prescriptions in Norway 2004-2015. Eur J Clin Pharmacol 2017; 73: 1173-9.

[PubMed][CrossRef]

4. Anderson SL, Vande Griend JP. Quetiapine for insomnia: A review of the literature. Am J Health Syst Pharm 2014; 71:394-402. [PubMed][CrossRef]

5. Thompson W, Quay TAW, Rojas-Fernandez C et al. Atypical antipsychotics for insomnia: a systematic review. Sleep Med 2016; 22: 13-7. [PubMed][CrossRef]

6. Atkin T, Comai S, Gobbi G. Drugs for insomnia beyond benzodiazepines: Pharmacology, clinical applications, and discovery. Pharmacol Rev 2018; 70: 197-245. [PubMed][CrossRef]

7. Tassniyom K, Paholpak S, Tassniyom S et al. Quetiapine for primary insomnia: a double blind, randomized controlled trial. J Med Assoc Thai 2010; 93: 729-34. [PubMed]

8. Karsten J, Hagenauw LA, Kamphuis J et al. Low doses of mirtazapine or quetiapine for transient insomnia: A randomised, double-blind, cross-over, placebo-controlled trial. J Psychopharmacol 2017; 31:327-37. [PubMed][CrossRef]

9. Trivedi MH, Bandelow B, Demyttenaere Ket al. Evaluation of the effects of extended release quetiapine fumarate monotherapy on sleep disturbance in patients with major depressive disorder: a pooled analysis of four randomized acute studies. Int J Neuropsychopharmacol 2013; 16: 1733-44. [PubMed][CrossRef]

10. Monti JM, Torterolo P, Pandi Perumal SR. The effects of second generation antipsychotic drugs on sleep variables in healthy subjects and patients with schizophrenia. Sleep Med Rev 2017;33: 51-7. [PubMed][CrossRef]

11. Fang F, Sun H, Wang Z et al. Antipsychotic drug-induced somnolence: Incidence, mechanisms, and management. CNS Drugs 2016; 30: 845-67. [PubMed][CrossRef]

12. Stahl SM. Stahls essential psychopharmacology. New York: Cambridge University Press, 2013.

13. Cornelis C, Van Gastel A, Dumont G et al. A case of dose escalation of quetiapine in persistent insomnia disorder. Acta Clin Belg 2017; 72:346-8. [PubMed][CrossRef]

14. Slørdal L, Bramness JG. Er alimemazin et egnet søvnmiddel for barn? Tidsskr Nor Lægeforen 20o8; 128: 2194-6. [PubMed]

15. Zhornitsky S, Potvin S, Moteshafi H et al. Dose-response and comparative efficacy and tolerability of quetiapine across psychiatric disorders: a systematic review of the placebo-controlled monotherapy and add-on trials. Int Clin Psychopharmacol 2011; 26: 183-92. [PubMed][CrossRef]

16. Williams SG, Alinejad NA, Williams JA et al. Statistically significant increase in weight caused by low-dose quetiapine. Pharmacotherapy 2010;30: 1011-5. [PubMed][CrossRef]

17. Cates ME, Jackson CW, Feldman JM et al. Metabolic consequences of using low-dose quetiapine for insomnia in psychiatric patients. Community Ment Health J 2009; 45: 251-4. [PubMed][CrossRef]

18. Coe HV, Hong IS. Safety of low doses of quetiapine when used for insomnia. Ann Pharmacother 2012; 46: 718-22. [PubMed][CrossRef]

19. Rittmannsberger H, Werl R. Restless legs syndrome induced by quetiapine: report of seven cases and review of the literature. Int J Neuropsychopharmacol 2013; 16:1427-31. [PubMed][CrossRef]

20. Aa E, Helland A, Spigset O. Kvetiapin kan ha misbrukspotensial. Tidsskr Nor Legeforen 2012; 132: 1619-20. [PubMed][CrossRef]

21. Bjorvatn B. Medikamentell behandling av insomni blant voksne. Nor Farm Tidsskr 2016; 124: 28-31. 22. Bjorvatn B, Sivertsen B, Waage S et al. Nasjonal kompetansetjeneste for søvnsykdommer. Nasjonal 
anbefaling for utredning og behandling av insomni. Søvn 2018; 10:12-7.

23. Riemann D, Baglioni C, Bassetti C et al. European guideline for the diagnosis and treatment of insomnia. J Sleep Res 2017; 26: 675-700. [PubMed][CrossRef]

24. Sateia MJ, Buysse DJ, Krystal AD et al. Clinical practice guideline for the pharmacologic treatment of chronic insomnia in adults: An american academy of sleep medicine clinical practice guideline. J Clin Sleep Med 2017; 13:307-49. [PubMed][CrossRef]

25. Bjorvatn B, Løge I, Jost PD. Søvnløshet. Norsk elektronisk legehåndbok.

https://legehandboka.no/handboken/kliniske-kapitler/psykiatri/tilstander-og-sykdommer/sovnforsty rrelser/sovnloshet/ Lest 5.6.2018.

26. Lee-Chiong T, Malik V. Insomnia. BMJ Best Practice. https://bestpractice.bmj.com/topics/en-gb/227 Lest 19.4.2018.

27. Winkelmann JW. Overview of the treatment of insomnia in adults. UpToDate versjon 3.o, 2018. https://www.uptodate.com/contents/overview-of-the-treatment-of-insomnia-in-adults Lest 10.9.2018.

28. Arnedt JT. Insomnia in patients with a substance use disorder. UpToDate versjon 12.0, 2018. https://www.uptodate.com/contents/insomnia-in-patients-with-a-substance-use-disorder Lest 23.8.2018.

29. European Medicines Agency. Questions and answers on Seroquel, Seroquel XR and associated names (quetiapine). EMA/301727/2014.

https://www.ema.europa.eu/en/documents/referral/questions-answers-seroquel-seroquel-xr-associate d-names-quetiapine_en.pdf Lest 23.4.2019.

30. U.S. Food and Drug Administration. Label information Seroquel. https://www.accessdata.fda.gov/drugsatfda_docs/label/2018/020639so6oso63lbl.pdf\#page=48 Lest 29.11.2018.

31. Gjerden P, Bramness JG, Slørdal L. Kvetiapin brukes for mye. Tidsskr Nor Legeforen 2018; 138. doi: 10.4045/tidsskr.18.0535. [PubMed][CrossRef]

32. Tanne JH. AstraZeneca pays \$520m fine for off label marketing. BMJ 2010;340: c2380.

[PubMed][CrossRef]

Publisert: 16. september 2019. Tidsskr Nor Legeforen. DOI: 10.4045/tidsskr.19.0205

Mottatt 12.3.2019, godkjent 23.4.2019.

(C) Tidsskrift for Den norske legeforening 2020. Lastet ned fra tidsskriftet.no 